\title{
OPEN In vitro regeneration and Agrobacterium-mediated genetic transformation of Dragon's Head plant (Lallemantia iberica)
}

\begin{abstract}
Rahman Ebrahimzadegan ${ }^{1}$ \& Asad Maroufi ${ }^{2 \bowtie}$
Dragon's head plant (Lallemantia iberica), is a flowering species belongs to the mint family (Lamiaceae). The species contains valuable essential oils, mucilage and oil which are used in pharmaceutical and food industries. Tissue culture is a feasible strategy to attain large-scale production of plantlets with a huge potential to produce plants with superior quality. The objective of this study was to develop a simple and efficient method for regeneration and transformation of $L$. iberica. To reach this goal, the regeneration ability of various explants including leaf, cotyledonary node, hypocotyl and cotyledon segments was investigated in MS medium supplemented with diverse concentrations of NAA (Naphthalene acetic acid) and BAP (6-Benzyl Amino Purine). According to the results, cotyledonary nodes showed the best regeneration response. The maximum rate of regeneration (and number of induced shoots was achieved in $1 \mathrm{mg} \mathrm{l}^{-1}$ BAP in combination with 0.05 $\mathrm{mg}^{-1}$ NAA from the cotyledonary nodes. Additionally, through the optimized regeneration technique Agrobacterium-mediated transformation of $L$. iberica was successfully accomplished. Gene transfer was assessed on leaf samples from regenerated plantlets under a fluorescent microscope to detect the GFP signals. Moreover, transgene integration and its expression were confirmed by PCR and RT-PCR analysis, respectively. The establishment of these efficient regeneration and genetic transformation methods paved the way for further application such as plant improvement, functional analysis and gene editing.
\end{abstract}

Lallemantia iberica, known generally as dragon's head, is a herb belonging to the mint family (Lamiaceae), originated from Caucasus and Middle East regions and widely distributed in Europe and some western areas of Asia ${ }^{1}$. L. iberica seeds are used in traditional medicine as stimulant, reconstitute, expectorant and diuretic. Its seeds contain large fatty acids like palmitic $6.5 \%$, stearic $1.8 \%$, oleic $10.3 \%$, linoleic $10.8 \%$ and linolenic $68 \%{ }^{2}$. Additionally Dragon's head plant comprises valuable secondary metabolites such as p-cymene, isophytol, t-cadinol, 3-octanol, terpinen-4- $\mathrm{ol}^{3}$. Moreover, its seed mucilage is used in the treatment of nervous, hepatica and renal diseases ${ }^{4}$. Additionally, this herb is mainly harvested for its seeds since they contain valuable oil compounds around $30 \%$ drying weight holding high amount of valuable omega 3 fatty acid and alpha-linolenic acid (67-74\%) which has many applications in pharma and food industries ${ }^{4,5}$. Lallemantia iberica is an attractive plant and because of its ornamental value it is used for landscaping and urban horticulture at various places ${ }^{6}$.

Since there is growing concerns over the side effects of chemical medications and the cost of these drugs, more attention has been focused on the use of natural and plant-derived compounds as an alternative or supplement. Therefore, the willingness to use medicinal plants and plant-derived secondary metabolites is increasing in the world. To meet this demand, cultivation of more medicinal plants or tissue culture to produce more natural products is essential. Plant tissue culture technique has several advantages and therefore, it has been used as a main platform for secondary metabolites production. In addition, plant tissue culture is considered to be the most efficient technology which used for basic and applied purposes such as, study of plant developmental processes, functional gene studies, micropropagation, generation of transgenic plants, plant breeding, virus-free plants production, preservation and conservation of germplasm of plants, and rescue of threatened or endangered plant species $^{7,8}$. Establishment of a reliable in vitro plant regeneration protocol is usually a prerequisite to the genetic transformation ${ }^{9}$. Improvement of plants with potential desired traits for instance greater quality, high yield,

${ }^{1}$ Department of Plant Production and Genetics, Faculty of Agriculture, University of Kurdistan, Sanandaj, Iran. ${ }^{2}$ Research Center for Medicinal Plant Breeding and Development, University of Kurdistan, Sanandaj, Iran. ${ }^{\circledR}$ email: a.maroufi@uok.ac.ir 
enhanced adaptability, disease and stress resistance based on plant biotechnological tools such as transformation is mostly depended on tissue culture technique ${ }^{10-12}$. Genetic transformation enables the introduction of foreign genes into L. iberica or efficient modification of target genes to create new cultivar with desirable traits such as higher valuable secondary metabolites or omega 3 fatty acid and alpha-linolenic acid. Moreover, in vitro regeneration and genetic transformation are important tools to enhance the production of secondary metabolites and engineer the valuable oil content in plants such as L. iberica. Actually Agrobacterium-mediated transformation has been frequently used to improve many plant species for several valuable traits ${ }^{13}$. Due to significant advantages of transformation using Agrobacterium, such as integration of transgene in the genome with low copy number, transgene stability in the host genome and efficient transformation, this is a preferred method comparing with other transformation systems ${ }^{14,15}$.

To the best of our knowledge, no well-organized method for transformation of L. iberica medicinal plant via Agrobacterium tumefaciens is available and only very limited studies have been performed on its regeneration ${ }^{6,16}$ and so far,. Therefore, for the first time an appropriate technique for in vitro regeneration and gene delivery using Agrobacterium are presented. This allows genetic improvements to be put into practice for Lallemantia iberica. In summary, the major factors which affect the regeneration and transformation such as, type of explants, concentrations or combinations of PGRs, acetosyringone, Agrobacterium inoculation duration, have been successfully optimized and a viable regeneration and transformation protocol well established.

\section{Material and methods}

In vitro seed germination. Dragon's Head plant seeds were procured from Pakanbazr an Iranian private joint stock company, providing deferent kinds of seeds to the customers (www.pakanbazr.com/en/lallemantiaiberica-seed). Using these seeds for research are not restricted according the role of University of Kurdistan, Sanandaj, Iran. This study meets national and international guidelines for research. The seeds were surface-sterilized by immersion in $70 \%$ ethanol for 30 s and immediately washing three times with sterilized distilled water, followed by soaking in 5\% sodium hypochlorite for $15 \mathrm{~min}$ and rinsing three times with sterilized distilled water. Next, the seeds were transferred into half strength Murashige and Skoog (MS) basal medium ${ }^{17}$ and incubated for germination under a photoperiod of $8 / 16 \mathrm{~h}$ dark/light using a $2400 \mathrm{~lx}$ light regime at $25 \pm 1{ }^{\circ} \mathrm{C}$.

In vitro plant regeneration. 21-day old seedlings grown in vitro, were used as source of explants for regeneration potential of $L$. iberica plants. The cotyledonary node, cotyledon, hypocotyl and leaf pieces were prepared in small segments about $0.5-1 \mathrm{~cm}^{2}$. The explants were separately cultured on MS medium containing four combinations of 6-Benzylaminopurine (BAP; 0, 0.5, 1 and $2 \mathrm{mg} \mathrm{l}^{-1}$ ) and 1-naphthaleneacetic acid (NAA; $0,0.05,0.1$ and $0.2 \mathrm{mg} \mathrm{l}^{-1}$ ). Afterwards, all cultures were incubated under a photoperiod of $8 / 16 \mathrm{~h}$ dark/light using a $2400 \mathrm{~lx}$ light regime at $25 \pm 1{ }^{\circ} \mathrm{C}$. For all plant growth regulator (PGR) combinations, 10 explants were incubated in each glass vessels. The explants were sub-cultured every two weeks and the number of regenerated shoots were finally recorded.

Root induction. The well regenerated shoots were cultured on MS supplemented with 4 concentrations of NAA $(0,0.1,0.5$ and $1 \mathrm{mg} / \mathrm{l})$ and incubated in culture room at $25 \pm 1{ }^{\circ} \mathrm{C}$. To evaluate the optimal concentrations of NAA for root induction all samples were daily monitored and data of rooting were collected.

Acclimatization of plantlets. The completely rooted plantlets were washed to remove the remains of MS medium, then transferred to small plastic pots containing 1:1 ratio of coco peat and perlite mix and totally covered with a transparent plastic shield. To adapt them to environmental condition, 2-3 small holes in the plastic wrap were daily created. Meanwhile, the plants were regularly irrigated with diluted liquid MS basal medium. After 3-4 weeks, the shield was entirely removed. Finally, the plantlets were transferred into the larger pots filled with 1: 1: 1 ratio of farm soil, compost and sand for more growth and evaluation.

Agrobacterium strain and binary vector. Agrobacterium tumefaciens strain C58C1Rif ${ }^{\mathrm{R}}$ (pMP90) containing pXK2FS7 binary vector has been utilized for transformation. It was kindly provided by Department of Plant Systems Biology (VIB, Ghent, Belgium). The genetic map of pXK2FS7 plasmid is shown in Fig. 1. It carries two reporter genes green fluorescent protein (GFP) and $\beta$-glucuronidase (GUS) that both are controlled under the CaMV 35S promoter ${ }^{18}$. To prepare the suspension culture of the Agrobacterium, a single colony obtained from the streaked LB agar petri plate incubated at $28{ }^{\circ} \mathrm{C}$, was first inoculated in liquid LB selective medium containing $50 \mathrm{mg} \mathrm{l}^{-1}$ rifampicin, $50 \mathrm{mg} \mathrm{l}^{-1}$ streptomycin and $25 \mathrm{mg} \mathrm{l}^{-1}$ gentamicin. Next the culture was incubated at $28^{\circ} \mathrm{C}$ on a shaker with $200 \mathrm{rpm}$ to achieve desired OD600 $=0.5-0.8$. Later on, the cells were collected by centrifugation at $5000 \mathrm{rpm}$ for $10 \mathrm{~min}$. The pellet was finally re-suspended in appropriate volume of liquid MS medium ( $\mathrm{pH} 7.8)$ for further use.

Agrobacterium-mediated transformation of explants. The cotyledonary node pieces were submerged in A. tumefaciens suspension $\left(\mathrm{OD}_{600}=0.6\right)$ for inoculation. The inoculated explants blotted dry on sterile Whatman paper under sterile conditions, then immediately transferred to co-cultivation medium (MS containing no PGRs and different concentrations of acetosyringone). The cultures were incubated in a dark chamber $\left(25 \pm 1{ }^{\circ} \mathrm{C}\right)$ for 3 days. Subsequently, the infected explants were washed three times with sterile distilled water, following with $50 \mathrm{ml}$ of cefotaxime solution $500 \mathrm{mg} \mathrm{l}^{-1}$ for $20 \mathrm{~min}$ to remove any trace of bacteria. The explants were gently blotted dry on sterile Whatman paper and directly cultured on regeneration medium (MS containing $1 \mathrm{mg} \mathrm{l}^{-1} \mathrm{BAP}$ and $0.05 \mathrm{mg} \mathrm{l}^{-1} \mathrm{NAA}$ ) having kanamycin at concentration of $60 \mathrm{mg} \mathrm{l}^{-1}$. After regeneration and 


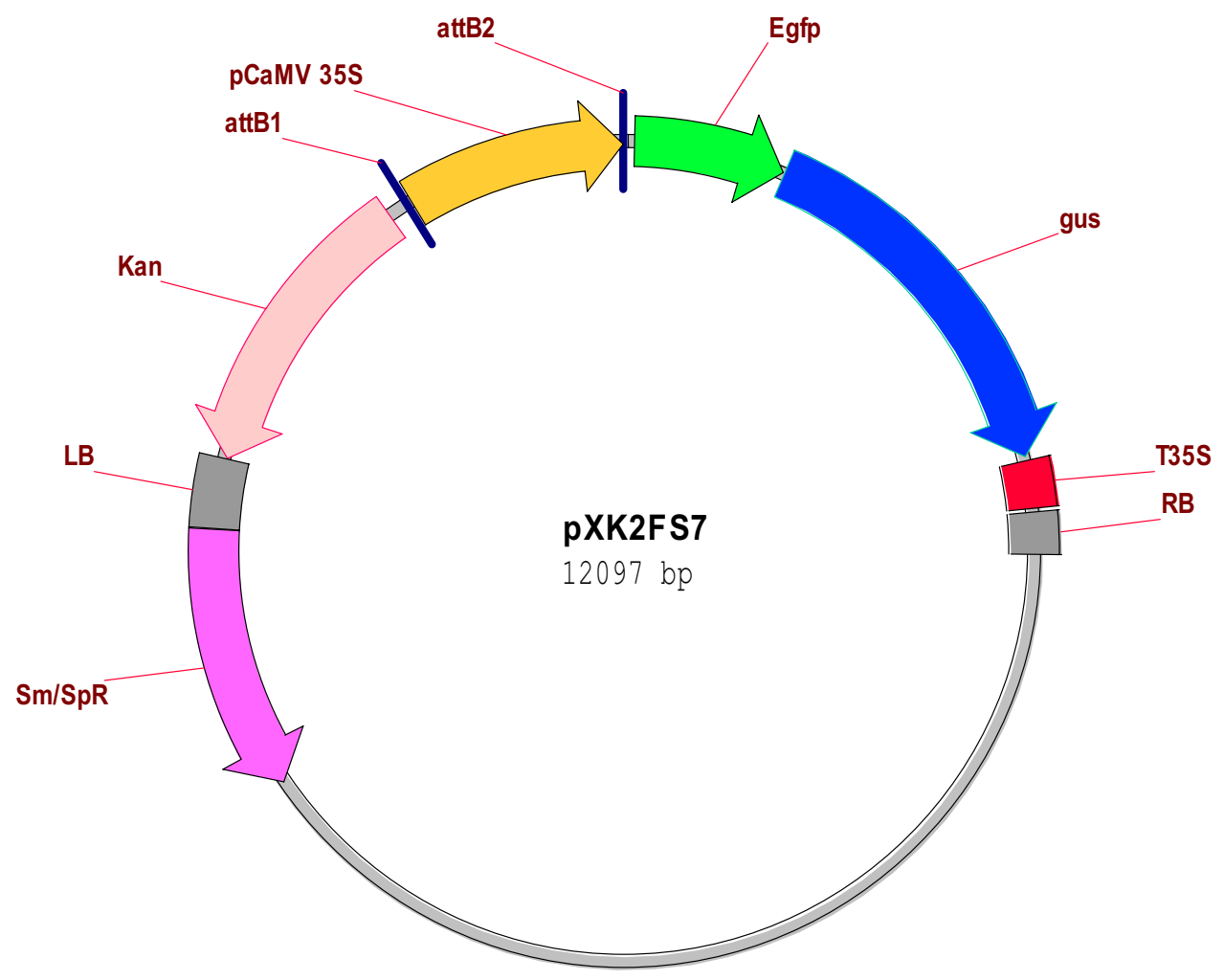

Figure 1. Genetic map of pXK2FS7 binary vector containing two reporter genes of GFP and GUS driven by the CaMV 35S promoter.

analysis of regenerated shoots by PCR, transformation efficiency (\%) was calculated as (The number of positive transgenic plants / the number of infected explants) $\times 100$.

Optimal kanamycin concentration. A sensitivity assessment was performed in order to find the optimal concentration of kanamycin, since it varies from species to species. The cotyledonary node explants were primarily cultured on regeneration medium containing different concentrations of kanamycin (0, 30, 60, 90 and 120 $\mathrm{mg} \mathrm{l}^{-1}$ ) and the number of survived explants was finally recorded for each kanamycin concentration.

Effect of infection time on transformation. To find the optimal infection time for transformation of L. iberica, in a separate experiment, explants were immersed in infective suspension of Agrobacterium (OD $\left.{ }_{600}=0.6\right)$ without acetosyringone for 4 certain infection time 10, 15, 20 and min. Following the transformation of explants, transformation efficiency was calculated.

Effect of acetosyringone on transformation. To study the effect of acetosyringone on transformation frequency, in a separate experiment, the suspension of Agrobacterium cells was supplemented with different concentration $(0,100,200$ and $300 \mu \mathrm{M})$ of acetosyringone for $15 \mathrm{~min}$. Following the transformation of explants, transformation efficiency was calculated.

Green fluorescent protein visualization. Green fluorescent protein visualisation was inspected in regenerated putative transgenic lines. Leaf samples were prepared from putative transgenic and non-transgenic plants. The leaf explants were exposed to blue ultraviolet light at excitation bandpass of $400 \mathrm{~nm}$ with a fluorescence Olympus BX51 microscope (Olympus, Japan) equipped with narrowband filter of 460-490 nm. Images were captured using a digital camera (Olympus, Japan) attached to a computer.

PCR characterization of the transgenic plants. Genomic DNA from putative transgenic and control plants was extracted using CTAB method ${ }^{19}$. The presence of a GFP and a GFP-GUS fragments were examined using polymerase chain reaction (PCR). The designed primers for GFP and GFP-GUS fragments were (F: 5'TCG TGACCACCCTGACCTAC3', R: 5'ACCTTGATGCCGTTCTTCTGC3') and (F: 5'AGGACGACGGCAACT ACAAG3', R: 5'TGACCCACACTTTGCCGTAA3') respectively. These primer pairs were basically designed to amplify a $310 \mathrm{bp}$ fragment of GFP and $711 \mathrm{bp}$ of GFP-GUS. The PCR reaction mix in a final volume of $50 \mu \mathrm{L}$ contained water, $50 \mathrm{ng}$ template DNA, 5 pmol of each primer, $2.5 \mathrm{mM}$ of each dNTPs, $2.5 \mathrm{mM} \mathrm{MgCl}_{2}$ and $0.5 \mathrm{U}$ of Taq polymerase. Amplification reaction was defined as follows; denaturation at $94^{\circ} \mathrm{C}$ for $5 \mathrm{~min}, 35$ subsequent cycles of $94{ }^{\circ} \mathrm{C}$ for $30 \mathrm{~s}$ (denaturation), $58^{\circ} \mathrm{C}$ for $30 \mathrm{~s}$ (annealing) and $72{ }^{\circ} \mathrm{C}$ for $45 \mathrm{~s}$ (polymerisation), and final 


\begin{tabular}{|l|l|l|l|l|}
\hline \multirow{2}{*}{ NAA $\left(\mathbf{m g ~ l}^{-1}\right)$} & BAP $\left(\mathbf{m g ~ l}^{-\mathbf{1}}\right)$ & $\mathbf{1}$ & $\mathbf{2}$ \\
\cline { 2 - 5 } & $\mathbf{0}$ & $\mathbf{0 . 5}$ & $\mathbf{1}$ & $59.66 \pm 5.50^{\text {ef }}$ \\
\hline 0 & $0.00 \pm 0.00$ & $86.33 \pm 6.50^{\mathrm{b}}$ & $68.33 \pm 4.04^{\mathrm{de}}$ & $55.33 \pm 4.04^{\mathrm{f}}$ \\
\hline 0.05 & $0.00 \pm 0.00$ & $84 \pm 3.46^{\mathrm{bc}}$ & $100 \pm 0.00^{\mathrm{a}}$ & $73 \pm 6.08^{\mathrm{cd}}$ \\
\hline 0.1 & $0.00 \pm 0.00$ & $73 \pm 7.00^{\text {cd }}$ & $100 \pm 0.00^{\mathrm{a}}$ & $100 \pm 0.00^{\mathrm{a}}$ \\
\hline 0.2 & $0.00 \pm 0.00$ & $82 \pm 10.14^{\mathrm{bc}}$ & $75.33 \pm 2.08^{\mathrm{bcd}}$ & \\
\hline
\end{tabular}

Table 1. Effect of different concentrations of BAP/ NAA on shoot regeneration frequency from cotyledonary nodes of $L$. iberica. Means with only the same letters are not significantly different at the $5 \%$ level based on Duncan's multiple range test $(p \leq 0.05)$. Data shown represent means of regeneration frequency $\pm \operatorname{SD}(n=3)$.

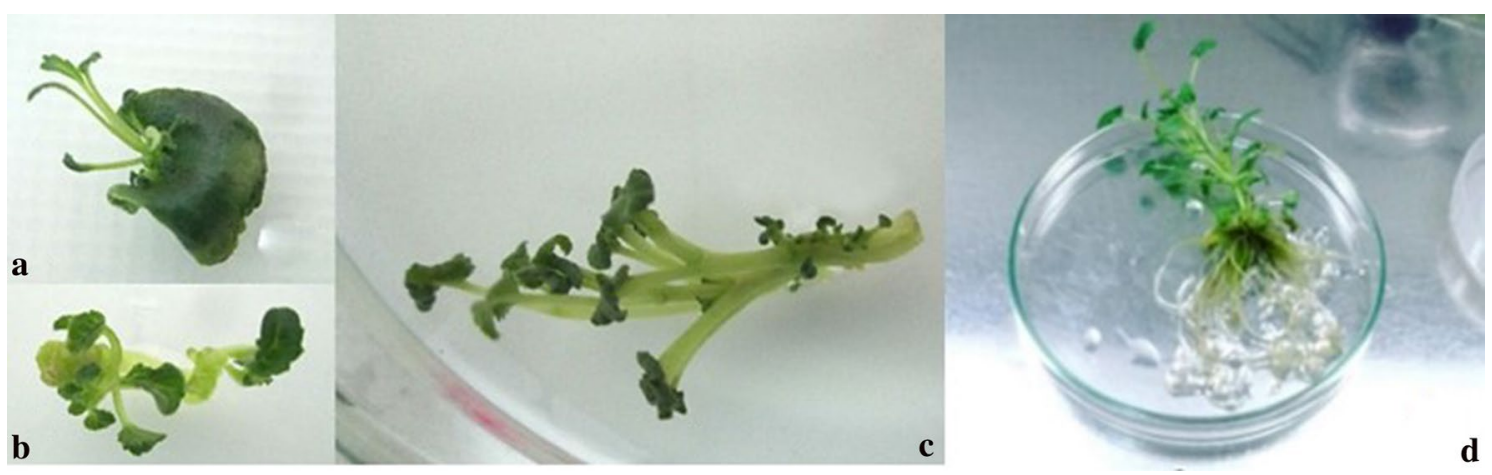

Figure 2. Response of explants on plant regeneration medium containing $1 \mathrm{mg} \mathrm{l}^{-1}$ BAP plus $0.05 \mathrm{mg} \mathrm{l}^{-1}$ NAA. (a,b) direct shoot formation after two weeks on cotyledonary node; (c) direct shoot regeneration from hypocotyl; (d) roots induced after two weeks on medium containing $0.1 \mathrm{mg} \mathrm{l}^{-1} \mathrm{NAA}$.

extension at $72{ }^{\circ} \mathrm{C}$ for $8 \mathrm{~min}$. The linear pXK2FS7 plasmid was used as the positive control. PCR products were finally visualised on $1.2 \%(\mathrm{w} / \mathrm{v})$ agarose gel.

Assessment of transgene expression. Total RNA was extracted from leaves of positive PCR transgenic and control plants (non-transgenic) using Mazzara and James method ${ }^{20}$. To avoid PCR amplification from genomic DNA, the RNA was treated with DNase I (DNAbiotech). First-strand cDNA was synthesized from total RNA using 2X HyperScript RT premix (GeneAll, South Korea) according to the manufacturer instructions. The cDNA was then used for PCR amplification of a $300 \mathrm{bp}$ of GFP using specific primers (F: 5'TCGTGACCACCC TGACCTAC3', R: 5'ACCTTGATGCCGTTCTTCTGC3'). PCR products were finally visualised on $1.2 \%(\mathrm{w} / \mathrm{v})$ agarose gel.

In vitro verification of stable transformation. To evaluate transient and stable transformation, in vitro regeneration of $\mathrm{T}_{0}$ generation was performed. The stem's nodes of confirmed transgenic plants were isolated, and cultured on the MS medium containing PGRs and $60 \mathrm{mg} \mathrm{l}^{-1}$ kanamycin. Following regeneration, a number of regenerated shoots were assessed using observation of GFP or molecular assessment (PCR and RT-PCR).

Data analysis. Treatments are assigned to a completely randomized design (CRD) with three replicates of ten explants. The data were analysed with SPSS 15.0 software package. Comparison of means was performed using Duncan's multiple range test $(p \leq 0.05)$.

\section{Results}

In vitro plant regeneration. In regeneration experiment, cotyledonary node, cotyledon, hypocotyl and leaf explants were examined on 16 different PGR combinations (Table 1). Cotyledonary nodes were able to directly regenerate shoots in all PGR combinations (Fig. 2a) except control (0 concentration of PGR) or media without BAP. But, no shoots or calli were obtained on cotyledon and leaf explants in the presence of the 16 combinations, nonetheless hypocotyls produced a few shoots only on the medium supplemented with $2 \mathrm{mg} \mathrm{l}^{-1}$ $\mathrm{BAP}+0.1 \mathrm{mg} \mathrm{l}^{-1} \mathrm{NAA}$ (Fig. 2, b and c). Shoot regeneration frequency (Table 1) and the number of induced shoots per explant (Table 2 ) in cotyledonary nodes were significantly varied in different combinations of NAA/ BAP. The highest regeneration rate $(100 \%)$ and number of induced shoots $(23 \pm 3.60)$ were observed in combination of $1 \mathrm{mg} \mathrm{l}^{-1} \mathrm{BAP}+0.05 \mathrm{mg} \mathrm{l}^{-1} \mathrm{NAA}$. However, other combinations resulted $100 \%$ regeneration occurrence but the number of induced shoots was significantly lower than of $1 \mathrm{mg} \mathrm{l}^{-1} \mathrm{BAP}+0.05 \mathrm{mg} \mathrm{l}^{-1} \mathrm{NAA}$ combination (Table 2). The lowest regeneration rate (59.66) was obtained from medium containing $2 \mathrm{mg} \mathrm{l}^{-1}$ BAP plus 0.05 $\mathrm{mg} \mathrm{l}^{-1} \mathrm{NAA}$ and the lowest number of induced shoots $(3.33 \pm 1.15 \%)$ was resulted in the medium containing $2 \mathrm{mg} \mathrm{l}^{-1}$ BAP (Table 1 and 2). Overall, different responses were observed in different explant types and bet- 


\begin{tabular}{|l|l|l|l|l|}
\hline \multirow{2}{*}{ NAA $\left(\mathbf{m g ~ l}^{-1}\right)$} & \multicolumn{4}{l|}{ BAP $\left(\mathbf{m g ~ l}^{-1}\right)$} \\
\cline { 2 - 5 } & $\mathbf{0}$ & $\mathbf{0 . 5}$ & $\mathbf{1}$ & $\mathbf{2}$ \\
\hline 0 & $0.00 \pm 0.00$ & $15 \pm 1.00^{\mathrm{bc}}$ & $13.33 \pm 1.52^{\mathrm{cd}}$ & $3.33 \pm 1.15^{\mathrm{g}}$ \\
\hline 0.05 & $0.00 \pm 0.00$ & $14.33 \pm 0.57^{\mathrm{bc}}$ & $23 \pm 3.60^{\mathrm{a}}$ & $6.33 \pm 2.00^{\mathrm{ef}}$ \\
\hline 0.1 & $0.00 \pm 0.00$ & $11.66 \pm 1.52^{\mathrm{d}}$ & $16.33 \pm 2.30^{\mathrm{b}}$ & $7.33 \pm 2.08^{\mathrm{e}}$ \\
\hline 0.2 & $0.00 \pm 0.00$ & $15 \pm 1.00^{\mathrm{bc}}$ & $14.33 \pm 2.51^{\mathrm{bc}}$ & $8.66 \pm 2.51^{\mathrm{e}}$ \\
\hline
\end{tabular}

Table 2. Number of induced shoots from cotyledonary node explants. Means with only the same letters are not significantly different at the $5 \%$ level based on Duncan's multiple range test $(p \leq 0.05)$. Data shown represent means of number of shoots $\pm \mathrm{SD}(n=3)$.

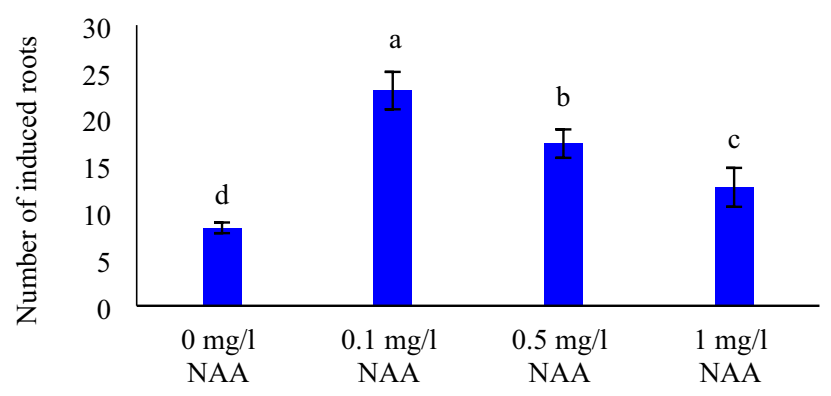

Figure 3. The effect of different concentrations of NAA on root induction. Means with only the same letters are not significantly different at the $5 \%$ level based on Duncan's multiple range test $(\mathrm{p} \leq 0.05)$. Data shown represent means of induced roots $\pm S D(n=3)$.

ter regeneration performance for cotyledonary node was obtained using 0.5 or $1 \mathrm{mg} \mathrm{l}^{-1}$ BAP in combination with some concentrations of NAA (Tables 1 and 2). Shoot regeneration from cotyledonary node and hypocotyl explants are presented in Fig. 2.

Root induction. Roots were initiated after nearby two weeks on in vitro-regenerated shoots cultured on MS medium with different concentrations of NAA (Fig. 2d). Maximum (23 \pm 2.00$)$ and minimum $(8.33 \pm 0.57)$ number of roots were induced in the medium supplemented with $0.1 \mathrm{mg} \mathrm{l}^{-1} \mathrm{NAA}$ and $0 \mathrm{mg} \mathrm{l}^{-1} \mathrm{NAA}$, respectively. Furthermore, by increasing the concentration of NAA over $0.1 \mathrm{mg} \mathrm{l}^{-1}$, number of induced roots was reduced $(p \leq 0.05)$ (Fig. 3).

Acclimatization of plantlets. The in vitro-regenerated shoots with well-developed root system were maintained in the acclimatization conditions for 4 weeks in the small plastic pots (Fig. $4 \mathrm{a}, \mathrm{b}, \mathrm{c}$ ) contain coco peat and perlite mix (1:1) and presented the best results with $100 \%$ survival rates. The plantlets were next transferred to the greenhouse into the larger pots filled with 1: 1: 1 ratio of farm soil, compost and sand (Fig. 4d), compost and sand and they grew and developed normally and morphologically were identical to the mother plant. Overall, the regenerated plants were morphologically normal, phenotypically stable, fertile, reproductive and able to set viable seeds (Fig. 4e).

Kanamycin tolerance assay. In the control ( 0 concentration of kanamycin), all explants exhibited normal growth and were healthy and green. On medium containing $30 \mathrm{mg} \mathrm{l}^{-1}$ kanamycin, some explants stopped growing (Fig. 5a) and their tissues turned brown after 30 days but most of them survived (66.66 $\pm 0.57 \%)$. In all other applied levels of kanamycin $\left(60,90\right.$ and $120 \mathrm{mg} \mathrm{l}^{-1}$, the explants were in poor condition and after two weeks they showed gradual whitening and finally stopped growing (Fig. 5b). Therefore, the concentration of $60 \mathrm{mg} \mathrm{l}^{-1}$ was designated as the effective level of kanamycin for selection of putative transgenic plants.

Plant transformation. Using optimized regeneration system, explant transformation was performed and finally several shoots were successfully induced from cotyledonary nodes in regeneration medium $\left(1 \mathrm{mg} \mathrm{l}^{-1}\right.$ BAP + $0.05 \mathrm{mg} \mathrm{l}^{-1} \mathrm{NAA}$ ) containing $60 \mathrm{mg} \mathrm{l}^{-1}$ kanamycin (Fig. 6a,b). Four weeks after culture, shoots were entirely developed (Fig. $6 \mathrm{c}$ ). The induced shoots were gently transferred into rooting medium (including 0.1 $\mathrm{mg} \mathrm{l}^{-1} \mathrm{NAA}$ ) (Fig. 6d,e,f). Finally, the rooted plants were acclimatized and hardened before moving them to the greenhouse for further analysis (Fig. $6 \mathrm{~g}$ ). There were no obvious phenotype differences between normal wild type and transgenic plants. They were fertile, reproductive and able to set viable seeds (Fig. 6h).

Effect of infection time on transformation efficiency. Analysis of variance showed that the effect of exposure time (treatment) of explants to Agrobacterium was significant. It means that the different infection time 


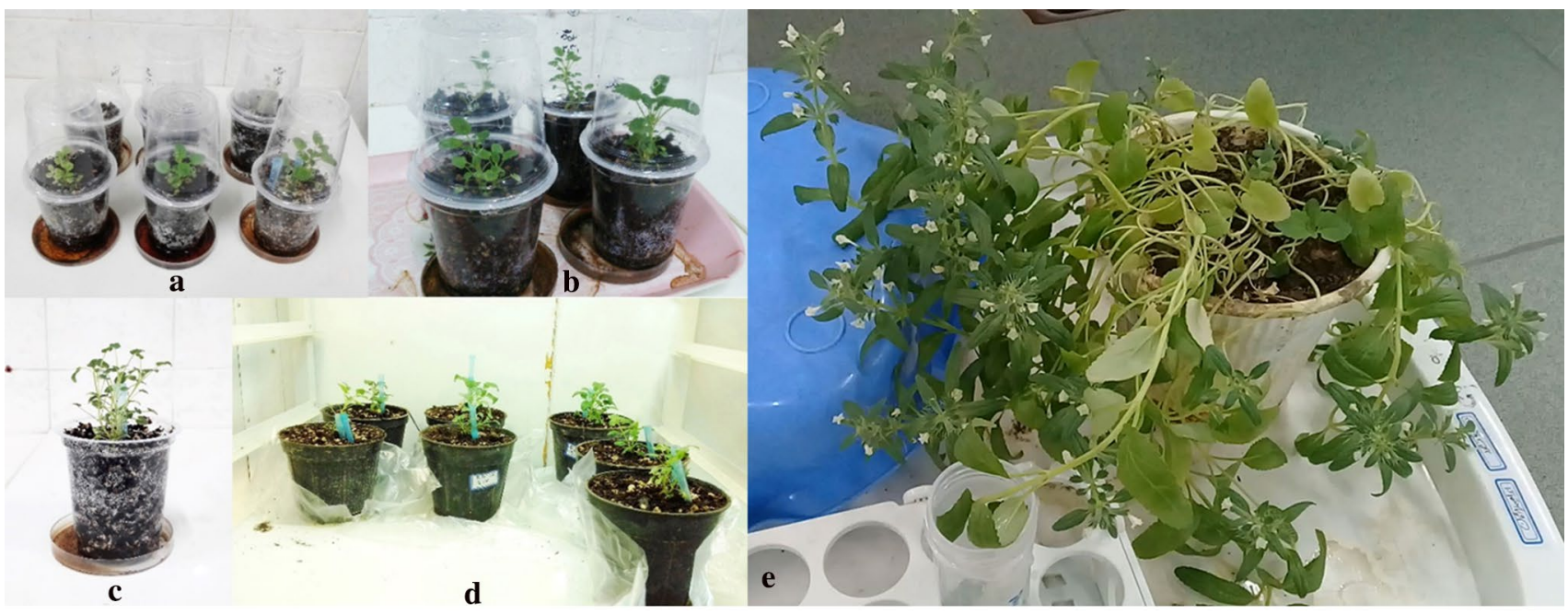

Figure 4. Acclimatization of regenerated plantlets. (a) The early stages of adaptation: transfer the plantlets to the pots containing 1:1 ratio of coco peat and perlite mix and covering them with transparent plastic shield; (b) making 2-3 holes in the shields to easy adapt plants; (c) removing of the plastic cover after 3-4 weeks; (d) transfer of plantlets to larger pots containing mixture of farm soil, compost, and sand at the late stage of adaptation; (e) a plant at flourishing stage.

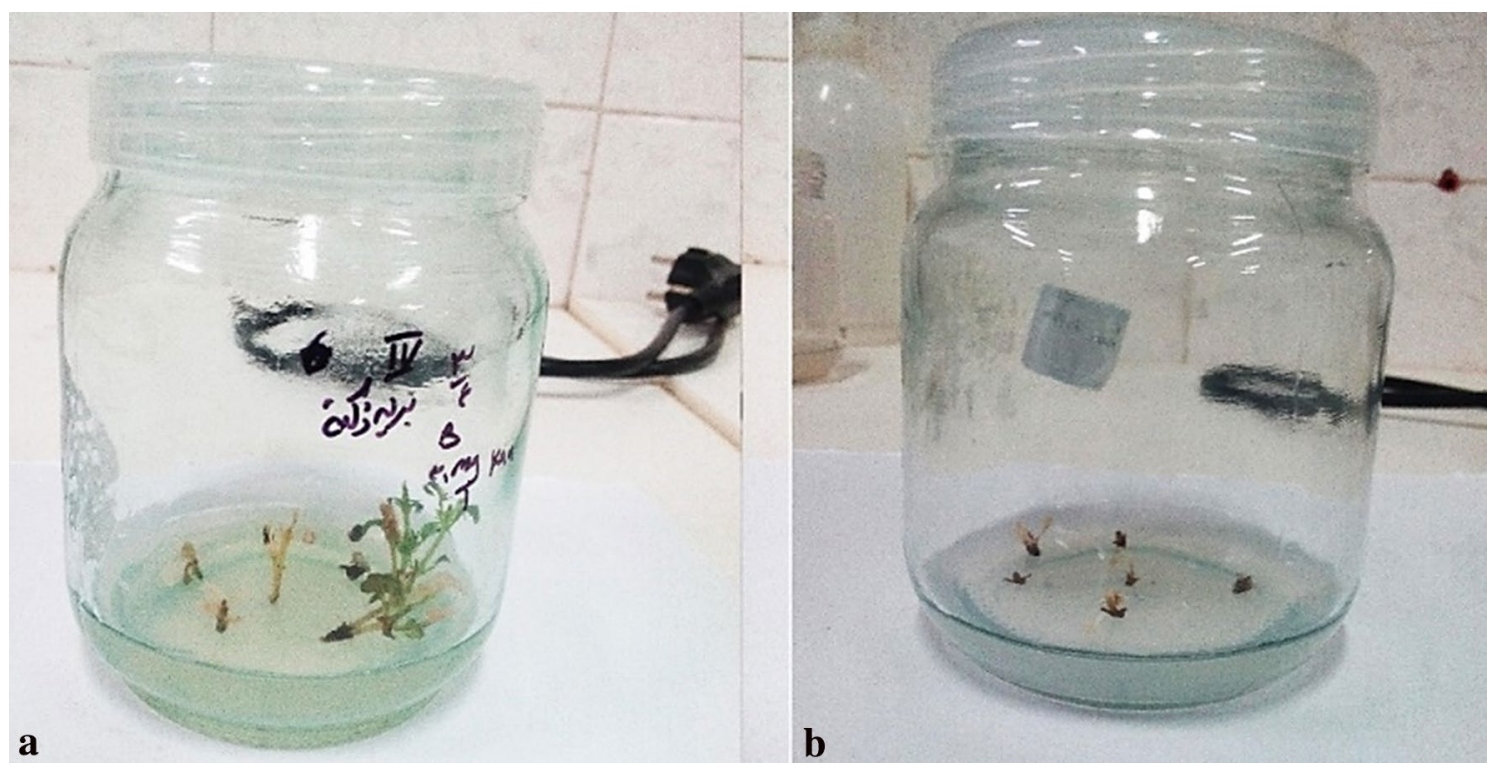

Figure 5. Explants on regeneration medium containing $30 \mathrm{mg} \mathrm{l}^{-1}$ and $60 \mathrm{mg} \mathrm{l}^{-1}$ kanamycin. (a) Explants on a medium containing $30 \mathrm{mg} \mathrm{l}^{-1}$ kanamycin after 3 weeks; (b) explants on a medium containing $60 \mathrm{mg} \mathrm{l}^{-1}$ kanamycin after 3 weeks.

resulted different transformation efficiency. Comparison of means using Duncan's multiple range test $(\mathrm{p} \leq 0.05)$ revealed that the highest transformation efficiency $(7 \pm 2.51 \%)$ was occurred at infection time of 15 min (Fig. 7a). By increasing of the infection period in Agrobacterium suspension, the transformation efficiency rates were considerably reduced (Fig. 7a).

Effect of acetosyringone on transformation efficiency. Maximum percentage of transformation $(6.66 \pm 0.33 \%)$ was achieved when acetosyringone was applied at $100 \mu \mathrm{M}$, however, presence or absence of acetosyringone did not significantly affect the transformation efficiency $(p \leq 0.05$; Fig. $7 \mathrm{~b})$. Higher concentrations of acetosyringone $(200$ and $300 \mu \mathrm{M})$ caused overgrowth of agrobacteria and browning of explants, ultimately leading to death of some explants.

Evaluation of transgenesis by GFP visualization. To confirm the transgene expression in regenerated plants after transformation, leaf samples of putative transgenic and non-transgenic plants (control) were investigated under fluorescence Olympus BX51 microscope (Olympus, Japan). All the collected sample leaves from 


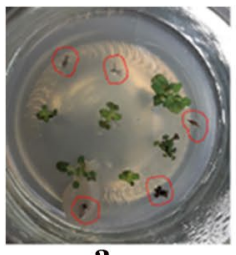

a

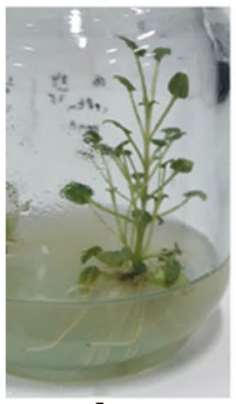

d

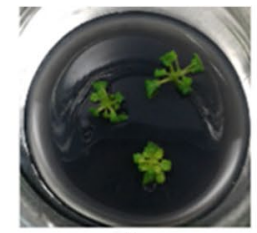

b

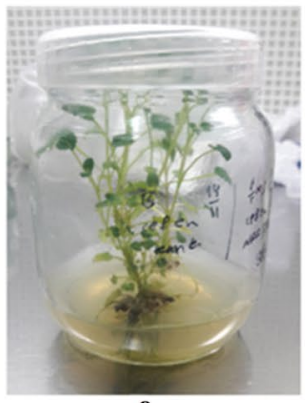

$\mathbf{e}$

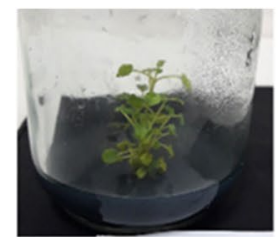

c

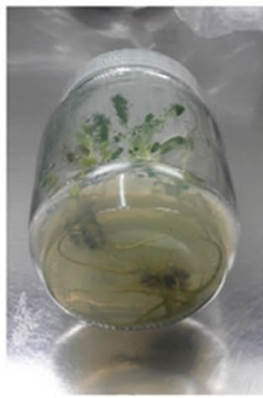

f

Figure 6. Regeneration of explants in selective medium containing $60 \mathrm{mg} \mathrm{l}^{-1}$ Kanamycin plus $400 \mathrm{mg} \mathrm{l}^{-1}$ cefotaxime after inoculation of explants with Agrobacterium cells. (a) Regeneration of putative transgenic plantlets (green plantlets) and non-transformed plantlets (Red circles) after two weeks of culture; (b) Subculturing of putative transgenic plantlets; (c) further development of plantlets in a new medium; (d,e,f) root initiation of regenerated shoot in MS medium containing $0.1 \mathrm{mg} \mathrm{l}^{-1} \mathrm{NAA}$ and $60 \mathrm{mg} \mathrm{l}^{-1}$ kanamycin; (g) acclimatized plantlets; (h) mature plant producing seeds; (i) $\mathrm{T}_{1}$ transgenic progeny plants.
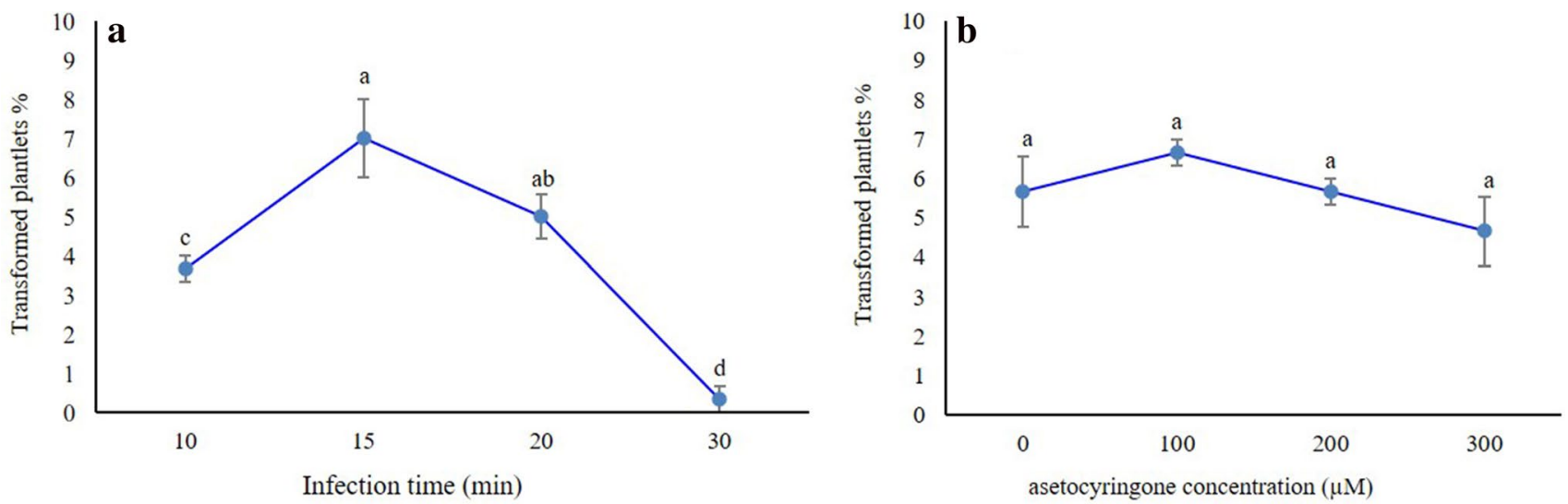

Figure 7. The effect of (a) different infection time and (b) concentrations of acetosyringone on gene transfer percentage. Means with only the same letters are not significantly different at the $5 \%$ level based on Duncan's multiple range test $(p \leq 0.05)$. Data shown represent means of transformation frequency $\pm \operatorname{SD}(n=3)$.

different putative transgenic plants exhibited obviously green fluorescence signals emitted by all leaf parts under UV excitation (Fig. 8a), while no signal of green fluorescence was observed in the non-transgenic leaf samples and they appeared red (Fig. 8b).

Confirmation of putative transgenic lines by PCR. PCR reactions were carried out using primers designed specifically for the DNA region of interest. Agarose gel profile representing the PCR products showed exact amplicons of $310 \mathrm{bp}$ for GFP (Fig. 9a) and $710 \mathrm{bp}$ for GFP-GUS (Fig. 9b) located on the T-DNA. No band was detected on genomic DNA of non-transgenic plants. The results of PCR confirmed the successful transfer and integration of T-DNA in different plants. DNA was also subjected to PCR to detect A. tumefaciens DNA and thus residual agrobacteria and samples were found to be negative (data not shown).

Analysis of transgene expression in transgenic plants. Transcript transgene expression was studied by RT-PCR. First, cDNA was synthesized from RNA samples of transgenic and non-transgenic plants which previously confirmed by PCR. RT-PCR was performed using specific primers to detect GFP transcript from transgenic plants. The RT-PCR product after agarose gel electrophoresis revealed an expected amplified fragment of 300 bp (Fig. 9c). While in non-transgenic plants no band was detected. This result confirmed successful integration and transcription of the genes on T-DNA in selected transgenic plants. 


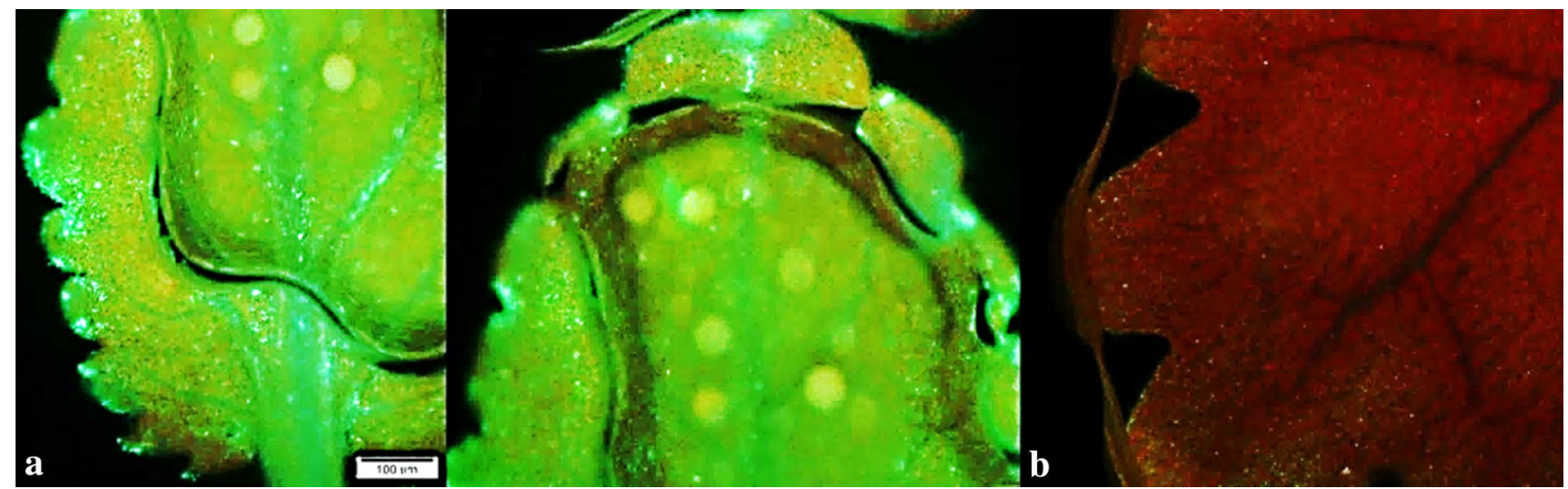

Figure 8. Green Fluorescence emission of green leaves from greenhouse-grown putative transgenic plants, (a) leaf sample from putative transgenic plant, (b) leaf segment of a wild-type plant (non-transgenic).

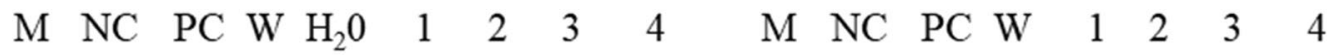
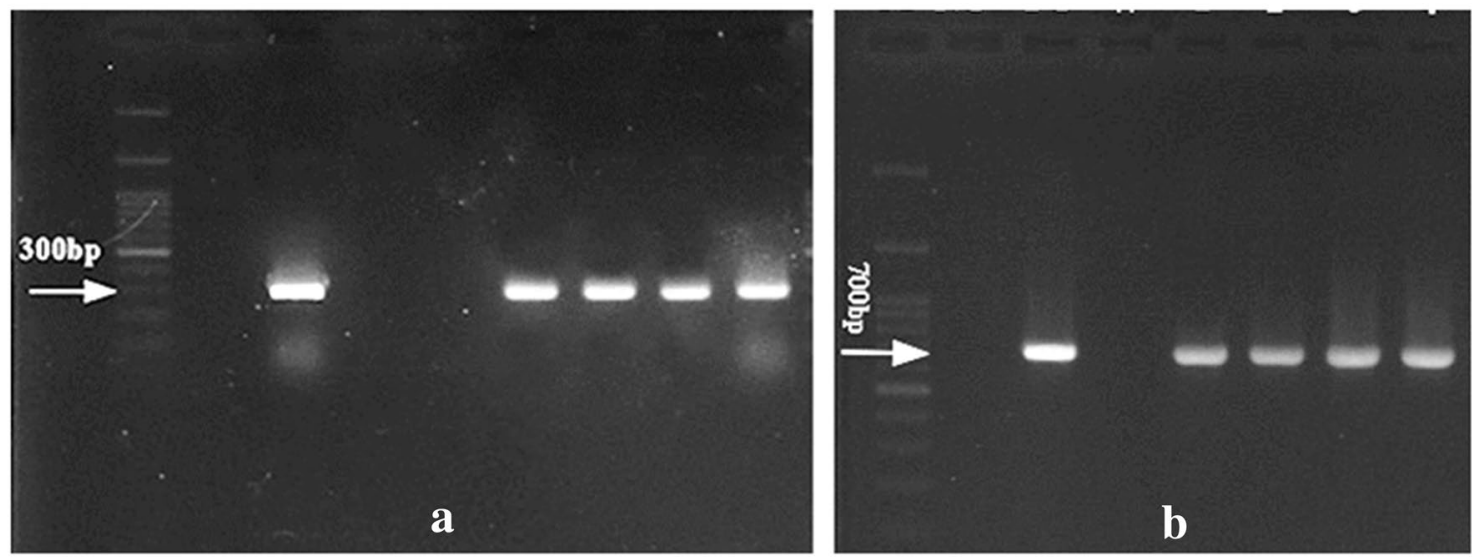

\section{$\begin{array}{lllllllll}\mathrm{M} & \mathrm{NC} & \mathrm{PC} & \mathrm{W} & \mathrm{H}_{2} \mathrm{O} & 1 & 2 & 3 & 4\end{array}$}

$\begin{array}{lllllllll}1 & 2 & 3 & 4 & \mathrm{PC} & \mathrm{W} & \mathrm{H}_{2} \mathrm{O} & \mathrm{M}\end{array}$
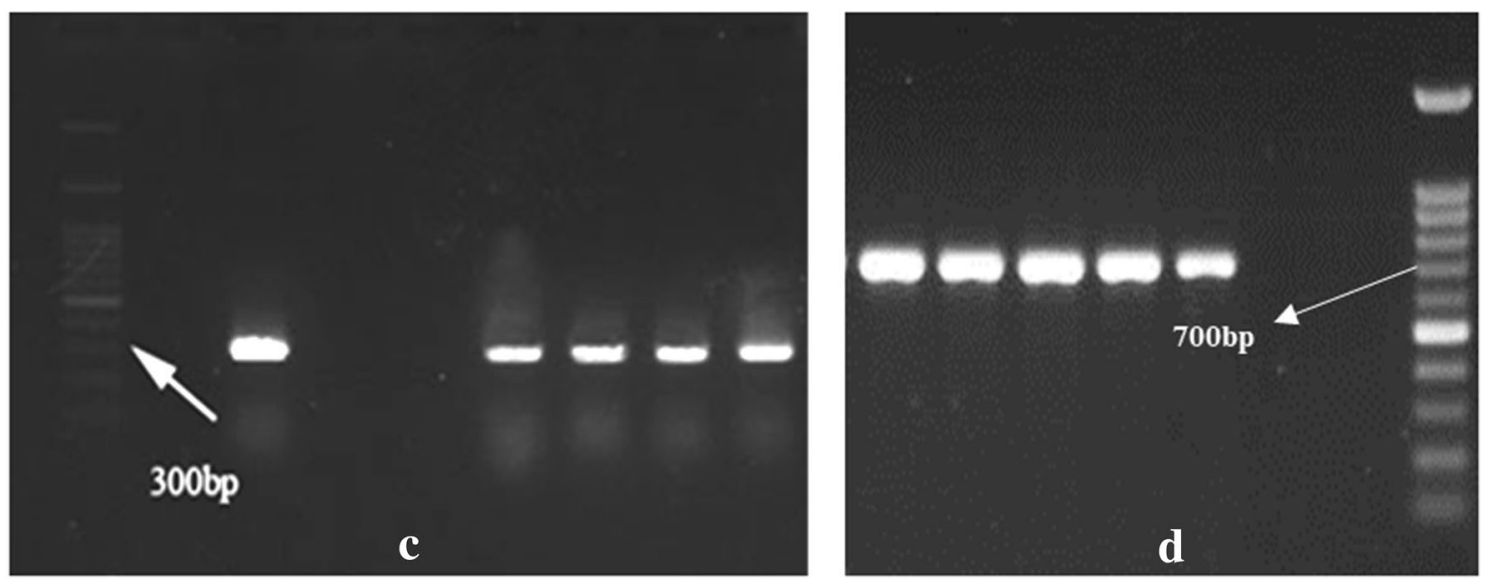

Figure 9. Gel electrophoresis of PCR on genomic DNA from the putative transgenic $\mathrm{T}_{0}$ plants using the (a) GFP and (b) GFP-GUS primers; (c) gel electrophoresis of PCR on cDNA from the putative transgenic $\mathrm{T}_{0}$ plants using the GFP primers (d) PCR on DNA from four $\mathrm{T}_{1}$ plants using the GFP-GUS primers. M) DNA Ladder 100 bp; NC) Negative Control; PC) Positive Control containing linear plasmid of binary vector; W) nontransgenic plants; lanes 1, 2, 3 and 4 are transgenic lines screened by GFP visualisation. 
Verification of stable transformation. The stem's nodes of confirmed $\mathrm{T}_{0}$ transgenic plants were subcultured onto the medium containing $60 \mathrm{mg} \mathrm{l}^{-1}$ kanamycin. Following the regeneration, a number of shoots were obtained. Leaf samples of the regenerated plants were evaluated under a fluorescence microscope. The GFP signals were effectively observed. In addition, the transgenic status of regenerated shoots was confirmed by PCR and RT-PCR and the targeted transgene fragments were detected. Additionally, PCR (Fig. 9d) was carried to detect a $711 \mathrm{bp} \mathrm{GFP-GUS} \mathrm{fragment} \mathrm{on} \mathrm{the} \mathrm{genomic} \mathrm{DNA} \mathrm{of} \mathrm{a} \mathrm{few} \mathrm{T}_{1}$ plants (progeny plants) derived from primary transgenic plants $\left(\mathrm{T}_{0}\right)$. $\mathrm{T}_{1}$ transgenic progeny plants did not show any considerable difference of morphological traits over the wild type plants (Fig. 6i).

\section{Discussion}

Plant tissue culture method has been used as an important approach for secondary metabolites production, micropropagation and it can assist breeding for the genetic modification and improvement of medicinal plants. Therefore, establishment of an efficient tissue culture system with several applications could be a prerequisite for L. iberica. In the present study, for the first time, we achieved in vitro regeneration and A.tumefaciens-mediated transformation of L. iberica. Regeneration experiment revealed that the cotyledonary nodes exhibited the highest regenerative capacity. Other explants except hypocotyl failed to develop any callus or shoot and turned brown at last. These results support the importance of evaluating different explant types when developing a plant regeneration protocol. Nodal sections normally exhibit a high regeneration response. The cotyledonary node usually has many meristematic cells; therefore, this enables cotyledonary node to produce directly a large number of shoots. Several studies have demonstrated that cotyledonary node was the most appropriate explant for regeneration ${ }^{21-23}$ and it performed best for in vitro regeneration or Agrobacterium-mediated transformation in several plant species such as Lupinus albus ${ }^{24}$, Passiflora caerulea . $^{25}$, Cicer arietinum L. ${ }^{26}$, Lallemantia iberica ${ }^{6}$, Glycine max $^{27}$ and Stevia rebaudiana Bertoni ${ }^{28}$.

The BAP in combination with NAA has been usually used for the shoot regeneration in various plant species $^{29-31}$. BAP appears to be one of the most efficient cytokinins for shoot generation from nodal segments and the success of shoot induction using BAP is very high ${ }^{32,33}$. In L. iberica the BAP/NAA combination, at certain concentration, was successfully induced in vitro shoots from cotyledonary nodes. The optimal concentration of BAP/NAA combination for shoot regeneration was $1 \mathrm{mg} \mathrm{l}^{-1}$ BAP plus $0.05 \mathrm{mg} \mathrm{l}^{-1} \mathrm{NAA}$ which led to induction of the highest number of shoots. In regeneration experiment of $L$. iberica the number of shoots were reduced by increasing the concentration of BAP to $2 \mathrm{mg}^{-1}$, such results have also been reported in grain legumes ${ }^{34,35}$. Although the higher concentration of cytokinin can induce the signal of shoot formation, it may also inhibit the normal growth of shoots and can form vitrified tissues because of their toxicity as this has been reported previously in other plant species ${ }^{36-39}$. We found different performance of various explants and different PGR combinations in L. iberica regeneration. Previous studies in several plant species have also discovered that many factors such as genotype, the nature of explant, culture media type, combination and concentration of plant growth regulators can influence shoot regeneration ${ }^{10,40,41}$.

In root induction study, cluster roots were produced at all concentrations of NAA, but the maximum number of roots were induced in the medium supplemented with $0.1 \mathrm{mg} \mathrm{l}^{-1} \mathrm{NAA}$. On this NAA concentration vigorous roots developed in normal shape with branched and whitish colour. Furthermore, by increasing NAA concentration, the number of roots were significantly decreased. These results are consistent with study of Hsieh and colleagues $^{42}$ which reported that the lowest concentration of NAA is appropriate to induce in vitro roots in Arachis hypogaea. Additionally, in Siratia grosvenorii the maximum roots observed in medium containing 0.1 $\mathrm{mg} \mathrm{l}^{-1} \mathrm{NAA}^{43}$. Indirect plant regeneration from callus is normally laborious and rely on different factors and additionally it might lead to somaclonal variation. Several researchers have declared that establishment of a tissue culture method for propagation and transformation from callus may result in genetic abnormalities ${ }^{44-47}$. Therefore, availability of a direct regeneration procedure is valuable for micropropagation and genetic transformation.

In Agrobacterium-mediated transformation experiment, two factors affecting gene transfer such as infection time and acetosyringone concentration were studied. The results showed that transformation efficiency of $L$. iberica was substantially affected by infection time, nonetheless the different concentrations of acetosyringone had no significant effect on transformation efficiency, although lower concentration of acetosyringone (100 $\mu M)$ induced higher transformation efficiency (Fig. 7b). Phenolic compounds such as acetosyringone and hydroxyacetosyringone, which attracts the agrobacteria to the wounded explants, also could induce the virulence genes, thus facilitating the transfer of the T-DNA region. Moreover, the transformation frequency might be negatively affected with the higher concentration of acetosyringone but the data was not statistically significant. Transformation efficiency was decreased at higher concentrations in other plant species such as Anthurium andraeanum ${ }^{48}$ and Vanda Kasem's Delight ${ }^{49}$. Moreover, by increasing the time of explant inoculation, the number of obtained transgenic plants were intensely decreased, and no transgenic was obtained in the time of $30 \mathrm{~min}$. Such effects of suitable time of inoculation on transformation efficiency was also reported in Ocimum gratissimum $^{39}$.

Effect of kanamycin at four concentrations $\left(0,30,60,90\right.$ and $\left.120 \mathrm{mg} \mathrm{l}^{-1}\right)$ on regeneration revealed that the concentration of $60 \mathrm{mg} / \mathrm{l}^{-1}$ resulted in a $66.66 \%$ shoot induction frequency. Regeneration on this kanamycin concentration was effective and gene transformation was finally confirmed by PCR and RT-PCR. Similar to our result, in Salvia miltiorrhiza, kanamycin at concentration of 30 and $60 \mathrm{mg} \mathrm{l}^{-1}$ was used to screen the transformant plantlets and the highest regeneration efficiency was obtained in the medium containing $60 \mathrm{mg} \mathrm{l}^{-150}$.

In addition to $n p t I I$ selectable marker, which is frequently used to select transformed plants, pXK2FS7 vector contains the GFP reporter gene. One advantage of GFP is that its expression analysis does not involve a destructive assay and visualization of GFP expression is performed with fluorescent microscopy allowing tracking progress throughout different stages ${ }^{51}$. In this study the putative transformant plants were initially screened using GFP signals. The use of green fluorescent protein (GFP) marker gene can reduce the time required for selection 
of transgenics ${ }^{52,53}$. Fluorescent marker genes allow visual detection and monitoring of transgene expression in transformed tissues and manual selection of transgenic plants even without using antibiotic or herbicide selection markers ${ }^{54,55}$. Detection of GFP signals under fluorescence microscope provided successfully the initial screening of transgenic plants that were finally confirmed by PCR and RT-PCR.

\section{Conclusion}

In this study, we established a preliminary in vitro procedure for direct regeneration of $L$. iberica using cotyledonary node and also a transformation system using A. tumefaciens. To our knowledge, this is the first report of Agrobacterium-mediated transformation of L. iberica which could provide feasible practical basis for genetic transformation and breeding of this valuable medicinal plant and it is expected to be of commercial value either by improvement of $L$. iberica seed oil or secondary metabolites. Also, genetic transformation provides a powerful tool to study of gene function and gene editing that will contribute to trait improvement, functional genomics and metabolite engineering.

Received: 21 August 2021; Accepted: 18 January 2022

Published online: 02 February 2022

\section{References}

1. Ursu, B. \& Borcean, I. Researches concerning the sowing technology at Lallemantia iberica. Res. J. Agric. Sci. 44(1), 168-171 (2012).

2. Overeem, A. et al. Seed oils rich in linolenic acid as renewable feedstock for environment-friendly crosslinkers in powder coatings. Ind. Crops Prod. 10, 157-165 (1999).

3. Morteza-Semnani, K. essential oil composition of Lallemantia iberica Fisch. et CA Mey. J. Essent. Oil Res. 18, 164-165 (2006).

4. Amanzadeh, Y., Khosravi Dehaghi, N., Gohari, A., Monsef-Esfahani, H. \& Sadat Ebrahimi, S. Antioxidant activity of essential oil of Lallemantia iberica in flowering stage and post-flowering stage. Res. J. Biol. Sci. 6, 114-117 (2011).

5. Gunstone, F. \& Harwood, J. Occurrence and characterisation of oils and fats, The lipid handbook with CD-ROM. CRC press, pp. 51-156 (2007).

6. Ozdemir, F.A., Yildirim, M.U. \& Pourali Kahriz, M. Efficient micropropagation of highly economic, medicinal and ornamental plant Lallemantia iberica (Bieb.) Fisch. and CA Mey. BioMed Research International Article ID 476346, (2014). https://doi.org/ $10.1155 / 2014 / 476346$

7. Stasolla, C. \& Thorpe, T.A. Tissue culture: historical perspectives and applications. In Applications of plant biotechnology: in vitro propagation, plant transformations and secondary metabolite production (eds Kumar, A. \& Sopory, S. K.) 1-39 (IK International, 2010).

8. Loyola-Vargas, V. M. \& Ochoa-Alejo, N. An introduction to plant tissue culture: Advances and perspectives. Methods Mol. Biol. 1815, 3-13. https://doi.org/10.1007/978-1-4939-8594-4_1 (2018) (PMID: 29981111).

9. Thorpe, T. A. History of plant tissue culture. Mol. Biotechnol. 37, 169-180 (2007).

10. effects of explant types and culture medium. Grozeva, S. \& Velkov, N. In vitro plant regeneration of two cucumber (Cucumis sativum L.) genotypes. Genetika 46, 485-493 (2014).

11. Lowe, K. et al. Rapid genotype "independent" Zea mays L. (maize) transformation via direct somatic embryogenesis. In Vitro Cell. Dev. Biol.-Plant 54, 240-252 (2018).

12. Farooq, N. et al. Investigating the in vitro regeneration potential of commercial cultivars of Brassica. Plants 8, 558 (2019).

13. Gelvin, S. B. Agrobacterium in the genomics age. Plant Physiol. 150, 1665-1676 (2009).

14. Dai, S. et al. Comparative analysis of transgenic rice plants obtained by Agrobacterium-mediated transformation and particle bombardment. Mol. Breeding 7, 25-33 (2001).

15. Travella, S. et al. A comparison of transgenic barley lines produced by particle bombardment and Agrobacterium-mediated techniques. Plant Cell Rep. 23, 780-789 (2005).

16. Pourebad, N., Motafakkerazad, R., Kosari-Nasab, M., Akhtar, N. F. \& Movafeghi, A. The influence of TDZ concentrations on in vitro growth and production of secondary metabolites by the shoot and callus culture of Lallemantia iberica. Plant Cell Tissue Organ Culture (PCTOC) 122, 331-339 (2015).

17. Murashige, T. \& Skoog, F. A revised medium for rapid growth and bio assays with tobacco tissue cultures. Physiol. Plant. 15, $473-497$ (1962).

18. https://gatewayvectors.vib.be/index.php/collection/pxk2fs7.

19. Khanuja, S. P., Shasany, A. K., Darokar, M. P. \& Kumar, S. Rapid isolation of DNA from dry and fresh samples of plants producing large amounts of secondary metabolites and essential oils. Plant Mol. Biol. Report. 17, 74-74 (1999).

20. Mazzara, M. \& James, D. J. The influence of photoperiodic growth condition on isolation of RNA from strawberry (Fragaria $\times$ ananassa Duch.) tissue. Mol. Biotechnol. 15, 237-241 (2000).

21. Paz, M. M., Martinez, J. C., Kalvig, A. B., Fonger, T. M. \& Wang, K. Improved cotyledonary node method using an alternative explant derived from mature seed for efficient Agrobacterium-mediated soybean transformation. Plant Cell Rep. 25, 206-213 (2006).

22. Yadav, S. K. et al. Optimization of Agrobacterium mediated genetic transformation of cotyledonary node explants of Vigna radiata. Springerplus 1, 1-8 (2012).

23. Behera, S. et al. Assessment of genetic and biochemical fidelity of field-established Hedychium coronarium J Koenig regenerated from axenic cotyledonary node on meta-topolin supplemented medium. Ind. Crops Prod. 134, 206-215 (2019).

24. Aslam, M. M. et al. In vitro regeneration potential of White Lupin (Lupinus albus) from Cotyledonary Nodes. Plants 9, 318 (2020).

25. Jafari, M., Daneshvar, M. H. \& Lotfi, A. In vitro shoot proliferation of Passiflora caerulea L. via cotyledonary node and shoot tip explants. J. Biotechnol. Comput. Biol. Bionanotechnol. 98, 113 (2017).

26. Sunil, S. P., Robinson, J. P., KarthickBalan, S., Anandhaprabhakaran, M. \& Balakrishnan, V. In vitro regeneration and induction of multiple shooting in Cicer arietinum L. using cotyledonary nodal explants. Afr. J. Biotechnol. 14, 1129-1138 (2015).

27. Zhang, F. et al. Efficient soybean regeneration and Agrobacterium-mediated transformation using a whole cotyledonary node as an explant. Biotechnol. Appl. Biochem. 61, 620-625 (2014).

28. Taak, P., Tiwari, S. \& Koul, B. Optimization of regeneration and Agrobacterium-mediated transformation of Stevia (Stevia rebaudiana Bertoni): a commercially important natural sweetener plant. Sci Rep 10, 16224. https://doi.org/10.1038/s41598-020-72751-8 (2020).

29. Rasool, R., Kamili, A. N., Ganai, B. A. \& Akbar, S. Effect of BAP and NAA on shoot regeneration in Prunella vulgaris. J. Natl. Sci. Math. 3(1), 21-26 (2009).

30. Al Gethami, F.R. \& El Sayed, H.E.S.A. In vitro: Influence of Various Concentrations of Plant Growth Regulators (BAP \& NAA) and Sucrose on Regeneration of Chenopodium quinoa Willd. Plant. Asian J. Biol. 9(4), 34-43 (2020). 
31. Deswiniyanti, N. W. \& Lestari, N. K. D. In vitro propagation of Lilium longiflorum Bulbs using NAA and BAP plant growth regulator treatment. KnE Life Sci. https://doi.org/10.18502/kls.v5i2.6437 (2020).

32. Weremczuk-Jeżyna, I., Kuźma, Ł, Kiss, A. K. \& Grzegorczyk-Karolak, I. Effect of cytokinins on shoots proliferation and rosmarinic and salvianolic acid B production in shoot culture of Dracocephalum forrestii W. W. Smith. Acta Physiol. Plant 40, 189. https://doi. org/10.1007/s11738-018-2763-z (2018).

33. Miguel, S. et al. In vitro plant regeneration and Agrobacterium-mediated genetic transformation of a carnivorous plant Nepenthes mirabilis. Sci. Rep. 10, 17482. https://doi.org/10.1038/S41598-020-74108-7 (2020).

34. Kartha, K., Pahl, K., Leung, N. \& Mroginski, L. Plant regeneration from meristems of grain legumes: soybean, cowpea, peanut, chickpea, and bean. Can. J. Bot. 59, 1671-1679 (1981).

35. Saka, H., Voqui-Dinh, T. H. \& Cheng, T.-Y. Stimulation of multiple shoot formation on soybean stem nodes in culture. Plant Sci. Lett. 19, 193-201 (1980).

36. Wang, B. et al. An efficient adventitious shoot regeneration system for ramie (Boehmeria nivea Gaud) using thidiazuron. Bot. Stud. 48, 173-180 (2007).

37. Abbasi, N. A., Pervaiz, T., Hafiz, I. A., Yaseen, M. \& Hussain, A. Assessing the response of indigenous loquat cultivar Mardan to phytohormones for in vitro shoot proliferation and rooting. J. Zhejiang Univ. Sci. B 14, 774-784 (2013).

38. Chiruvella, K. K., Mohammed, A. \& Ghanta, R. G. Phenotypic aberrations during micropropagation of Soymida febrifuga (Roxb.) Adr. Juss. Notulae Scientia Biologicae 6, 99-104 (2014).

39. Khan, S., Fahim, N., Singh, P. \& Rahman, L. U. Agrobacterium tumefaciens mediated genetic transformation of Ocimum gratissimum: a medicinally important crop. Ind. Crops Prod. 71, 138-146 (2015).

40. Yan, M.-M. et al. Effects of explant type, culture media and growth regulators on callus induction and plant regeneration of Chinese jiaotou (Allium chinense). Sci. Hortic. 123, 124-128 (2009).

41. Gourguillon, L., Lobstein, A. \& Gondet, L. Effects of explant type, culture media and growth regulators for callus induction of a potential bioactive halophyte: Armeria maritima (Plumbaginaceae). Planta Medica 82(S 01), S1-S381 (2016). https://doi.org/10. 1055/s-0036-159679582.

42. Hsieh, Y.-F., Jain, M., Wang, J. \& Gallo, M. Direct organogenesis from cotyledonary node explants suitable for Agrobacteriummediated transformation in peanut (Arachis hypogaea L). Plant Cell Tissue Organ Cult. 128, 161-175 (2017).

43. Yan, H., Liang, C., Yang, L. \& Li, Y. In vitro and ex vitro rooting of Siratia grosvenorii, a traditional medicinal plant. Acta Physiol. Plant. 32, 115-120 (2010).

44. Li, R., Stelly, D. M. \& Trolinder, N. L. Cytogenetic abnormalities in cotton (Gossypium hirsutum L.) cell cultures. Genome 32, 1128-1134 (1989).

45. Stelly, D. M., Altman, D., Kohel, R., Rangan, T. \& Commiskey, E. Cytogenetic abnormalities of cotton somaclones from callus cultures. Genome 32, 762-770 (1989).

46. Choi, H., Lemaux, P. \& Cho, M. J. Increased chromosomal variation in transgenic versus nontransgenic barley (Hordeum vulgare L.) plants. Crop Sci. 40, 524-533 (2000).

47. Bregitzer, P. \& Tonks, D. Inheritance and expression of transgenes in barley. Crop Sci. 43, 4-12 (2003).

48. Hosein, F. N., Lennon, A. M. \& Umaharan, P. Optimization of an Agrobacterium-mediated transient assay for gene expression studies in Anthurium andraeanum. J. Am. Soc. Hortic. Sci. 137, 263-272 (2012).

49. Gnasekaran, P., Antony, J. J., Uddain, J. \& Subramaniam, S. Agrobacterium-mediated transformation of the recalcitrant Vanda Kasem's Delight orchid with higher efficiency. ScientificWorldJournal. https://doi.org/10.1155/2014/583934 (2014).

50. Yan, Y.-P. \& Wang, Z.-Z. Genetic transformation of the medicinal plant Salvia miltiorrhiza by Agrobacterium tumefaciens-mediated method. Plant Cell Tissue Organ Cult. 88, 175-184 (2007).

51. Swartwood, K. \& Van Eck, J. Development of plant regeneration and Agrobacterium tumefaciens-mediated transformation methodology for Physalis pruinosa. Plant Cell Tiss Organ Cult. 137, 465-472. https://doi.org/10.1007/s11240-019-01582-x (2019).

52. Leclercq, J. et al. The green fluorescent protein as an efficient selection marker for Agrobacterium tumefaciens-mediated transformation in Hevea brasiliensis (Mull. Arg). Plant Cell Rep. 29, 513-522 (2010).

53. Mishra, M. K. et al. Green fluorescent protein as a visual selection marker for coffee transformation. Biologia 65, 639-646. https:// doi.org/10.2478/s11756-010-0078-7 (2010).

54. Miki, B. \& McHugh, S. Selectable marker genes in transgenic plants: applications, alternatives and biosafety. J. Biotechnol. 107, 193-232 (2004).

55. Hraška, M., Rakouský, S. \& Čurn, V. Green fluorescent protein as a vital marker for non-destructive detection of transformation events in transgenic plants. Plant Cell Tissue Organ Cult. 86, 303-318 (2006).

\section{Acknowledgements}

The authors would like to acknowledge Ms. Pegah Shahidi for technical assistance.

\section{Author contributions}

A.M. conceived the idea, designed the experiment, supervised the project and revised the manuscript. R.E set up the in vitro culture and transformation method, performed analysis and prepared the manuscript.

\section{Competing interests}

The authors declare no competing interests.

\section{Additional information}

Correspondence and requests for materials should be addressed to A.M.

Reprints and permissions information is available at www.nature.com/reprints.

Publisher's note Springer Nature remains neutral with regard to jurisdictional claims in published maps and institutional affiliations. 
(c) (i) Open Access This article is licensed under a Creative Commons Attribution 4.0 International cc) License, which permits use, sharing, adaptation, distribution and reproduction in any medium or format, as long as you give appropriate credit to the original author(s) and the source, provide a link to the Creative Commons licence, and indicate if changes were made. The images or other third party material in this article are included in the article's Creative Commons licence, unless indicated otherwise in a credit line to the material. If material is not included in the article's Creative Commons licence and your intended use is not permitted by statutory regulation or exceeds the permitted use, you will need to obtain permission directly from the copyright holder. To view a copy of this licence, visit http://creativecommons.org/licenses/by/4.0/.

(C) The Author(s) 2022 